\title{
Effects of Bisphenol A (BPA) on Placentation and Survival of the Neonates in Mice
}

\author{
Toru TACHIBANA ${ }^{1)}$, Yuki WAKIMOTO ${ }^{1)}$, Nobuaki NAKAMUTA ${ }^{2)}$, \\ Thanmaporn PHICHITRASLIP1), Shoichi WAKITANI ${ }^{3)}$, Ken KUSAKABE ${ }^{4)}$, \\ Eiichi HONDO ${ }^{1,3)}$ and Yasuo KISO ${ }^{1,3)}$
}

1) Laboratory of Basic Veterinary Science, United Graduate School of Veterinary Science, Yamaguchi University, Yamaguchi 753-8515, ${ }^{2}$ First Department of Oral Anatomy, Kyushu Dental College, Kokura 853-8580, ${ }^{3)}$ Department of Veterinary Anatomy and Cell Biology, Faculty of Agriculture, Yamaguchi University, Yamaguchi 753-8515 and ${ }^{4)}$ Department of Anatomy and Biology, Osaka Medical College, Takatsuki 569-8686, Japan

\begin{abstract}
The effects of bisphenol A (BPA) on placentation have not been fully determined. The aim of this study was to clarify the structural changes of the placenta, abortion rate, and survival of neonates after BPA administration in mice. BPA $(10 \mathrm{mg} / \mathrm{kg} /$ day $)$ was administered to pregnant mice (BPA mice) subcutaneously from the first day of pregnancy (Day 0) to Day 7 (8 days total). The number of embryos and weights of whole uteri were measured on Days 10 and 12. Morphological changes in the placentae were examined by light microscopy on the corresponding days of pregnancy. The number of neonates was also counted. Survival rates were periodically calculated for neonates from the first day after parturition (P-Day 0) to P-Day 56. The number of embryos and weight of the uterus on Days 10 and 12 were significantly decreased by BPA injection. No notable differences were recognized between the left and right uteri. The proportion of the labyrinthine zone per whole placenta in the BPA mice became lower than that in the controls, and that of the metrial gland was higher in the BPA mice. The intervillous spaces of the placenta were narrower in the BPA mice. Degenerative changes were found in the trophoblastic giant cells and spongiotrophoblast layers of the BPA mice. The number of BPA mouse neonates was drastically decreased within 3 days after birth, and no mice survived after P-Day 56. The results suggest that BPA not only disrupts placental functions and leads to abortion through chronic stimulation of gene expression by binding to DNA but that it also affects the mortality of neonates through indirect exposure of embryos.
\end{abstract}

Key words: Bisphenol A, Placenta, Neonate, Mouse, Survival rate

(J. Reprod. Dev. 53: 509-514, 2007)

B isphenol A (BPA: 2,2-Bis(4-hydroxyphenyl)propane) interacted with estrogen receptors (ERs) and has weak estrogen activity (approximately $1 / 10,000$ of $17 \beta$-estradiol affinity to ERs) [1]. BPA, which is an endocrine disruptor, has

Accepted for publication: December 26, 2006

Published online: March 23, 2007

Correspondence: E. Hondo (e-mail: ehondo@yamaguchiu.ac.jp) been used as a basic ingredient in polycarbonate and/or epoxy resin [2,3]. Therefore, plastic containers for household use and/or dental sealants contain BPA [4]. Problems due to exposure of humans to BPA via these products have arisen in recent years. For example, BPA was detected at concentrations of up to $30 \mu \mathrm{g} / \mathrm{ml}$ in saliva from patients who had dental sealants applied to their teeth [4]. 
The effects of BPA on female reproductive organs and the weights of the uterus are increased by administration of high doses of BPA (up to $800 \mathrm{mg}$ / $\mathrm{kg})[5,6]$. Injection of BPA $(500 \mathrm{mg} / \mathrm{kg})$ to ovariectomized rats caused a $67 \%$ increase in uterine weight and proliferation of uterine stromal cells [7]. A medium dose of BPA $(30 \mathrm{mg} / \mathrm{kg})$ resulted in a $37 \%$ increase in the uterine weights of ovariectomized Sprague-Dawley rats [8]. Differences in response to BPA among rat strains and grafting of the capsule to release a low dose of BPA $(0.3 \mathrm{mg} / \mathrm{kg} /$ day) subcutaneously increased the uterine weight and height of the uterine luminal epithelial cells in ovariectomized F344 rats [9]. On the other hand, no detectable changes were observed in the Sprague-Dawley rats used in the same experiment as the F344 rats [9].

The effects of BPA on the pregnant uterus have not been fully examined. Although DNA microarray has shown that the mRNAs of some nuclear receptors in the mouse placenta are increased by BPA administration [10], no detailed information is currently available about the effect of BPA on placentation and/or the fate of embryos and neonates. The present study shows the morphological changes in the pregnant uterus during placentation after BPA administration in mice. Embryo and neonate mortality was also investigated.

\section{Materials and Methods}

Ten to 12-week-old virgin mice (ICR strain; Clea Japan, Osaka, Japan) were used in this study. They were housed under a $12 \mathrm{~h}$ light and dark cycle and were provided with water and food ad libitum. The first day of pregnancy (Day 0) was defined as the day when a vaginal plug was detected. The first day after birth was designated P-Day 0. All experimental procedures were based on the guidelines of the committee for animal welfare at Yamaguchi University.

BPA (Wako Chemicals, Osaka, Japan) dissolved in sesame oil (Sigma-Aldrich, St. Louis, MO, USA) was injected into the mice subcutaneously for 8 days from Day 0 to Day 7. Mice injected with vehicle from Day 0 to Day 7 were used as the control. Placentae were excised under pentobarbital anesthesia on Days 10 and 12. After counting the number of embryos and measuring the uterine weight, all placentas were fixed in Bouin's solution. Uterine weight per body weight of the mother was calculated. In addition, the number of neonates was counted to calculate the survival rates of neonates for P-Day 0 to 3 and PDay 56 using the following formula: the number of living neonates/the number of dead neonates. Values were evaluated by one-way ANOVA. For light microscopy, fixed tissues were dehydrated in a graded series of ethanol, infiltrated in xylene, and embedded in paraffin wax. Paraffin sections were prepared at $4 \mu \mathrm{m}$ thickness and stained with hematoxylin and eosin. The thickness of the layers of the whole placenta, metrial gland, deciduas basalis, and placental labyrinth were measured using sections with the maximum thickness for the layer of the whole placenta, and the proportions of each tissue were calculated as follows: metrial gland/whole placenta, desidua basalis/whole placenta, and placental labyrinth/whole placenta. Mean values for the thickness of each layer were calculated using 5 serial sections from 5 individuals. Each value was statistically analyzed by Welch's $t$-test after examining equal variance by F-test.

\section{Results}

The number of embryos, uterine weights, and proportions of uterine weight per body weight of the mother are shown in Table 1 . All indexes were significantly lower in the BPA mice than in the controls on Days 10 and 12. There were no differences between the left and right uteri (data not shown).

The metrial gland, decidua basalis, and placental labyrinth were easily discriminated for both the control and BPA mice (Fig. 1a and b), although the spongiotrophoblastic layer could not be clearly located at low magnification in the BPA mice on Day 12. The placentae of the controls were larger than those of the BPA mice on Day 12 (Table 2), although no significant difference was detectable between the BPA mice and controls on Day 10. The difference in the proportions of each tissue were less conspicuous on Day 10 than on Day 12. The proportions of the metrial gland were significantly higher in the BPA mice than in the controls on Day 12. On the other hand, the proportions of the decidua basalis and placental labyrinth were 
Table 1. Effects of BPA on abortion and uterine weight

\begin{tabular}{llccr}
\hline & & Number of embryos & Uterine weight $(\mathrm{g})$ & Uterine weight $(\%)$ \\
\hline Day 10 & Control & $16.2 \pm 1.64^{\mathrm{a}}$ & $2.184 \pm 0.109^{\mathrm{b}}$ & $5.31 \pm 0.444^{\mathrm{c}}$ \\
Day 10 & BPA & $4.6 \pm 1.14^{\mathrm{a}}$ & $0.542 \pm 0.063^{\mathrm{b}}$ & $1.40 \pm 0.098^{\mathrm{c}}$ \\
Day 12 & Control & $16.4 \pm 2.61^{\mathrm{d}}$ & $5.706 \pm 0.657^{\mathrm{e}}$ & $12.97 \pm 1.740^{\mathrm{f}}$ \\
Day 12 & BPA & $4.8 \pm 0.84^{\mathrm{d}}$ & $1.144 \pm 0.038^{\mathrm{e}}$ & $2.63 \pm 0.221^{\mathrm{f}}$ \\
\hline
\end{tabular}

Values with the same superscript letters are significantly different $(\mathrm{P}<0.01)$.

Values are shown as the mean \pm SD $(n=5)$.

significantly lower in the BPA mice than in the controls on Day 12. There were no detectable changes in the proportions of the decidua basalis between the BPA and control mice on Day 10 .

No abnormalities were found in formation of the network of fetal blood vessels in the BPA mice. On the other hand, the intervillous spaces, through which maternal blood flows, were narrowed in the BPA mice on Days 10 and 12 (Fig. 1c and d). Trophoblastic giant cells, which usually form a band at the boundary line between the decidua basalis and placental labyrinth in normal mice, were not sequentially aligned in the BPA mice (Fig. 1c and d). The BPA mice had fewer glycogencontaining cells and thinner spongiotrophoblastic layers than the controls (Fig. 1e and f). The survival rate of the control neonates was almost $100 \%$ within 56 days of birth. Approximately two thirds of the BPA neonates that were born alive died within a day after birth (Fig. 2). Most of the neonates were unable to survive for three days. None survived at 56 days after birth.

\section{Discussion}

This study revealed that administration of BPA at a dose of $10 \mathrm{mg} / \mathrm{kg}$ from Day 0 to 7 leads to reductions in the number of embryos and uterine weight and influences placentation, especially development of the decidua basalis and trophoblastic layers. In addition, BPA decreased the number of neonates and increased their mortality.

Estrogen is important for successful pregnancy. Estrogen regulates migration of the embryo by affecting muscular layers in the oviduct [11] and induction of embryonic implantation to the uterus [12]. A single estrogen surge in the morning on Day 3 is the first signal for initiation of implantation in normal mice $[13,14]$. Leukemia inhibitory factor
(LIF), which can substitute for estrogen, is induced immediately after estrogen and is essential for successful implantation [12]. LIF leads to apoptotic cell death of the luminal epithelial cells at the point of embryo attachment to the uterus, and this is followed by decidualization and closure of the luminal epithelium at implantation sites [15, 16]. BPA might disrupt the motility of muscular layers of the oviduct and/or the above sequential phenomena of embryo implantation by binding estrogen receptors, ultimately resulting in a reduction of the number of embryos during pregnancy.

The decrease in uterine weight in this study contradicts the findings of previous reports of BPA administration experiments for rats $[5,6,8,9,17]$. The decrease in this study might have resulted from fetal loss during pregnancy. This study does not disprove the possibility that there are species differences between mice and rats in the terms of response of the uterus to BPA.

Although the thickness of the whole placenta decreased, the proportion of the metrial gland to the whole placenta increased in the BPA mice. The actual thickness of the metrial gland was thick compared with the controls (Table 1, Fig. 1a and b). Estrogen receptors are localized in the luminal epithelium, glandular epithelium, and/or stromal cells of the uterus from Days 1 to $8[18,19]$. BPA probably stimulates stromal cells constantly, and BPA administration probably causes hyperplasia of the metrial gland after irreversible binding of its metabolites to the DNA of the stromal cells in each of these tissues [20]. There might be other mechanisms of BPA signaling in the decidua basalis and trophoblastic layers, since the reverse phenomenon to hyperplasia appeared between the decidua basalis and metrial gland. The effects of BPA on trophoblasts are probably indirect via constant stimulation of other cells by BPA because trophoblasts do not have estrogen receptors [18, 

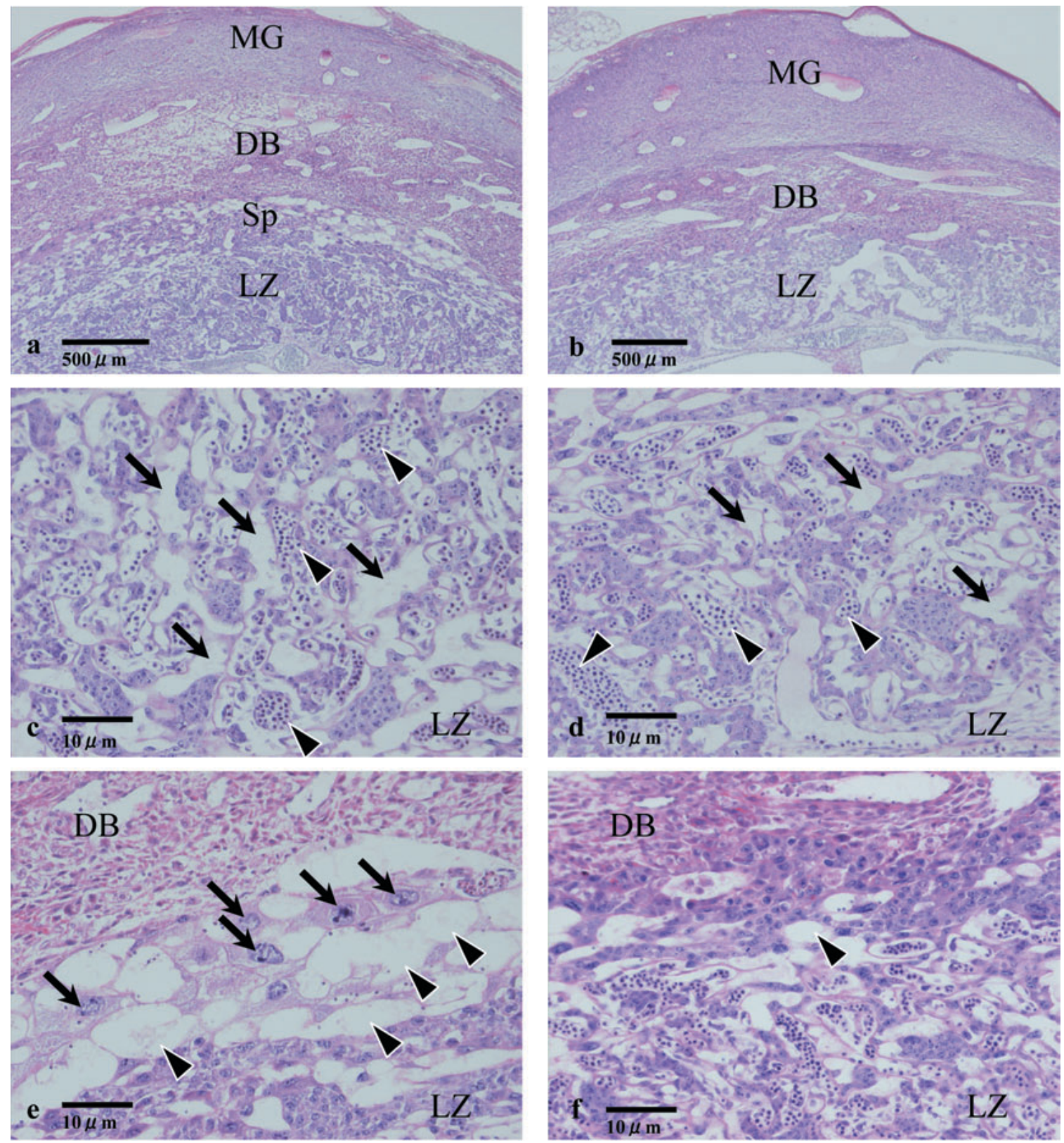

Fig. 1. Cross sections of a placenta on Day 12. H-E staining. $a, c$, e: the placentae of control mice. $b$, $d$, $f$ : the placentae of BPA mice. c, d: arrows show intervillous spaces in which maternal blood flows; capillaries of the embryo are shown by arrowheads. The intervillous spaces in BPA mice (d) are narrowed compared with the control (c). e, f: trophoblastic giant cells are aligned at the border of the decidua basalis and placental labyrinth (arrows). Glycogen-containing cells (arrowheads) are larger and more frequently recognized in the controls than in the BPA mice. MG: metrial gland. DB: decidua basalis. Sp: spongiotrophoblast layer. LZ: labyrinthine zone.

19]. The trophoblastic giant cells of the BPA mice were poorly developed in this study. It has been suggested that trophoblastic giant cells controlled maternal blood flow [21] and that their angiogenic factors are important for successful placentation
$[22,23]$. BPA possibly binds to cell species other than trophoblasts and disrupt cytokine networks involved in trophoblastic functions. The intervillous spaces, which are formed by trophoblasts and through which maternal blood 
Table 2. Morphological changes in the placentae of BPA mice

\begin{tabular}{llcccc}
\hline & & Whole placenta $(\mu \mathrm{m})$ & Metrial gland $(\%)$ & Decidua basalis $(\%)$ & Placental labyrinth $(\%)$ \\
\hline Day 10 & Control & $1798 \pm 81.31$ & $25.2 \pm 2.28^{\mathrm{a}}$ & $36.8 \pm 1.83$ & $38.0 \pm 0.88^{\mathrm{b}}$ \\
Day 10 & BPA & $1903 \pm 34.69$ & $39.7 \pm 1.29^{\mathrm{a}}$ & $38.4 \pm 1.83$ & $22.7 \pm 1.11^{\mathrm{b}}$ \\
Day 12 & Control & $2401 \pm 51.60^{\mathrm{c}}$ & $22.9 \pm 1.36^{\mathrm{d}}$ & $33.0 \pm 2.16^{\mathrm{e}}$ & $44.0 \pm 1.90^{\mathrm{f}}$ \\
Day 12 & BPA & $1814 \pm 39.98^{\mathrm{c}}$ & $42.0 \pm 0.99^{\mathrm{d}}$ & $27.1 \pm 1.80^{\mathrm{e}}$ & $30.9 \pm 1.50^{\mathrm{f}}$ \\
\hline
\end{tabular}

Values with the same superscript letters are significantly different $(\mathrm{P}<0.01)$. Values are shown as the mean $\pm \mathrm{SD}(\mathrm{n}=5)$.

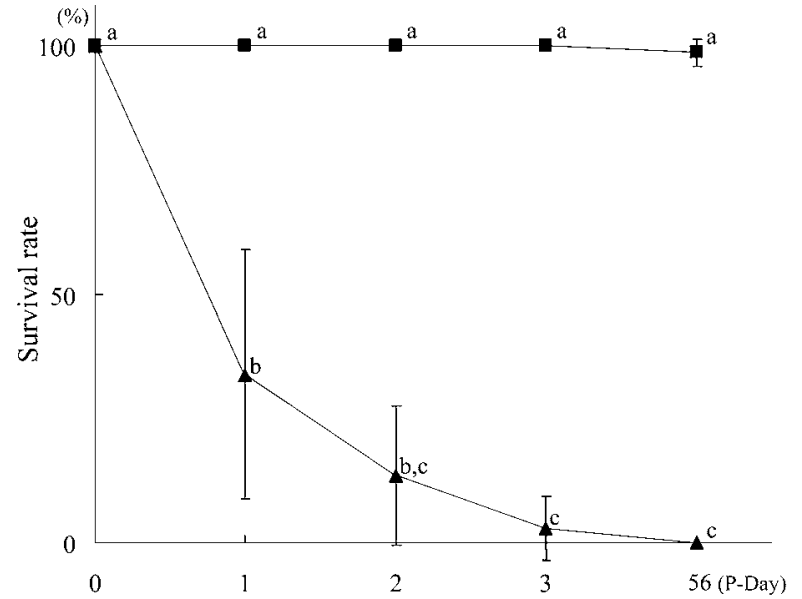

Fig. 2. Survival rates after birth. A drastic decrease was recognized in these rates within 3 days after birth. None survived at P-Day 56. $\square$ : survival rates of control mice. $\boldsymbol{\Delta}$ : survival rates of BPA mice. Values are shown as means \pm SD. Values with different letters are significantly different $(\mathrm{P}<0.05)$.

flows, were ultimately narrowed in the BPA mice. Development of glycogen-containing cells was also disturbed by BPA. These cells, which are control of BPA signaling, may be partly under the control of estrogen. BPA administered to the mother transits to embryos via the placenta [24]. BPA has a tendency to remain in fetuses longer than in maternal blood [24]. The decrease in the number of fetuses in this study might have been caused by the direct effect of BPA on fetuses. In fact, microarray analysis has shown that BPA induces some nuclear receptor mRNAs after they bind to the estrogen receptor [10]. The effects of BPA on cytokine production should be examined at the protein level.

The reduction in the number of neonates and increased mortality of the BPA neonates are consistent with previous results when a high dose of BPA was administered to pregnant mice [25]. Polychlorinated biphenyl (PCB), diethylhexyl phthalate (DEHP), and /or dichloro-diphenyltrichloroethane (DDT), which are representative endocrine disruptors, bind to estrogen receptors [7], decrease the number of embryos and neonates, and increase the mortality of neonates. Comparative morphological evaluation of the placenta with administration of not only BPA but also the other above-mentioned molecules is important for assessment of the effects of estrogen receptor binding disruptors on placentation.

BPA also influences parental care for neonates [26]. The extremely low survival rate in this study probably resulted from not only spontaneous disorder of the neonate by indirect exposure to BPA in the first trimester of pregnancy, but also behavioral abnormality by the mother, although we could not detect any behavioral disorders in the mothers in this study.

\section{Acknowledgement}

This study was partly supported by Grants-inAid for Scientific Research (No. 12306015 and 16780204) from the Japanese Ministry of Education, Culture, Sports, Science and Technology.

\section{References}

1. Witorsch RJ. Low-dose in utero effects of xenoestrogens in mice and their relevance to humans: an analytical review of the literature. Food Chem Toxicol 2002; 40: 905-912.
2. Staples CA, Dorn PB, Klecka GM, O'Block ST, Harris LR. A review of the environmental fate, effects, and exposures of bisphenol A. Chemosphere 1998; 36: 2149-2173. 
3. Brotons JA, Olea-Serrano MF, Villalobos $\mathbf{M}$, Pedraza V, Olea N. Xenoestrogens released from lacquer coatings in food cans. Environ Health Perspect 1995; 103: 608-612.

4. Olea N, Pulgar R, Perez P, Olea-Serrano F, Rivas A, Novillo-Fertrell A, Pedraza V, Soto AM, Sonnenschein C. Estrogenicity of resin-based composites and sealants used in dentistry. Environ Health Perspect 1996; 104: 298-305.

5. John A. Increasing the sensitivity of the rodent uterotrophic assay to estrogens, with particular reference to bisphenol A. Environ Health Perspect 2001; 109: 1091-1094.

6. Ashby J, Tinwell H. Uterotrophic activity of bisphenol A in the immature rat. Environ Health Perspect 1998; 106: 719-720.

7. Cook JC, Kaplan AM, Davis LG, O'connor JC. Development of a Tier I screening battery for detecting endocrine-active compounds (EACs). Regul Toxicol Pharmacol 1997; 26: 60-68.

8. Dodge JA, Glasebrook AL, Magee DE, Phillips DL, Sato M, Short LL, Bryant HU. Environmental estrogens: effects on cholesterol lowering and bone in the ovariectomized rat. J Steroid Biochem Mol Biol 1996; 59: 155-161.

9. Steinmetz R, Mitchner NA, Grant A, Allen DL, Bigsby RM, Ben-Jonathan N. The xenoestrogen bisphenol A induces growth, differentiation, and cfos gene expression in the female reproductive tract. Endocrinology 1998; 139: 2741-2747.

10. Imanishi S, Manabe N, Nishizawa $\mathbf{H}$, Morita $\mathbf{M}$, Sugimoto M, Iwahori M, Miyamoto $H$. Effects of oral exposure of bisphenol A on mRNA expression of nuclear receptors in murine placentae assessed by DNA microarray. J Reprod Dev 2003; 49: 329-336.

11. Ascher E, Madelenat P, Rose D. Tubal physiology: structures and functions. J Gynecol Obstet Biol Reprod (Paris) 1986; 15: 717-729.

12. Chen JR, Cheng JG, Shatzer T, Sewell L, Hernandez L, Stewart CL. Leukemia inhibitory factor can substitute for nidatory estrogen and is essential to inducing a receptive uterus for implantation but is not essential for subsequent embryogenesis. Endocrinology 2000; 141: 4365-4372.

13. Finn CA, Martin L. The control of implantation. J Reprod Fertil 1974; 39: 195-206.

14. McCormack JT, Greenwald GS. Evidence for a preimplantation rise in oestradiol-17beta levels on day 4 of pregnancy in the mouse. J Reprod Fertil 1974; 41: 297-301.

15. Schere-Levy C, Buggiano V, Quaglino A, Gattelli A, Cirio MC, Piazzon I, Vanzulli S, Kordon EC. Leukemia inhibitory factor induces apoptosis of the mammary epithelial cells and participates in mouse mammary gland involution. Experi Cell Res 2003; 282: 35-47.

16. Fouladi Nashta AA, Andreu CV, Nijjar N, Heath
JK, Kimber SJ. Role of leukemia inhibitor factor (LIF) in decidualisation of murine uterine stromal cells in vitro. J Endocrinol 2004; 81: 477-492.

17. Papaconstantinou AD, Umbreit TH, Fisher BR, Goering PL, Lappas NT, Brown KM. Bisphenol Ainduced increase in uterine weight and alteration in uterine morphology in ovariectomized B6C3F1 mice: role of the estrogen receptor. Toxicol Sci 2000; 56: 332-339.

18. Tan J, Paria BC, Dey SK, Das SK. Differential uterine expression of estrogen and progesterone receptors correlates with uterine preparation for implantation and decidualization in the mouse. Endocrinology 1999; 140: 5310-5321.

19. Ogle TF, Dai D, George P, Mahesh VB. Stromal cell progesterone and estrogen receptors during proliferation and regression of the decidua basalis in the pregnant rat. Biol Reprod 1997; 57: 495-506.

20. Atkinson A, Roy D. In vitro conversion of environmental estrogenic chemical bisphenol A to DNA binding metabolite(s). Biochem Biophys Res Commun 1995; 210: 424-433.

21. Dong YL, Vegiraju S, Chauhan M, Yallampalli C. Expression of calcitonin gene-related peptide receptor components, calcitonin receptor-like receptor and receptor activity modifying protein 1 , in the rat placenta during pregnancy and their cellular localization. Mol Hum Reprod 2003; 9: 481490.

22. Gagioti S, Scavone C, Bevilacqua E. Participation of the mouse implanting trophoblast in nitric oxide production during pregnancy. Biol Reprod 2000; 62: 260-268.

23. Abbott BD, Buckalew AR. Placental defects in ARNT-knockout conceptus correlate with localized decreases in VEGF-R2, Ang-1, and Tie-2. Dev Dyn 2000; 219: 526-538.

24. Domoradzki JY, Pottenger LH, Thornton CM, Hansen SC, Card TL, Markham DA, Dryzga MD, Shiotsuka RN, Waechter JM Jr. Metabolism and pharmacokinetics of bisphenol A (BPA) and the embryo-fetal distribution of BPA and BPAmonoglucuronide in CD Sprague-Dawley rats at three gestational stages. Toxicol Sci 2003; 76: 21-34.

25. Reel JR, Tyl RW, Lawton AD, Lamb JC. Bisphenol A: Reproduction and fertility assessment in CD-1 mice when administered in the feed. Report to the National Toxicology Program from Research Triangle Institute, Research Triangle Park, NC, USA. [NTIS PB86-103207]

26. vom Saal FS, Cooke PS, Buchanan DL, Palanza P, Thayer KA, Nagel SC, Parmigiani S, Welshons WV. A physiologically based approach to the study of bisphenol A and other estrogenic chemicals on the size of reproductive organs, daily sperm production, and behavior. Toxicol Ind Health 1998; 14: 239-260. 